\title{
The problem of digital transformation of Russian universities
}

\author{
Nelly Savelyeva ${ }^{1, *}$, Natalie Nevraeva ${ }^{1}$, Alexander Kabanov ${ }^{1}$, Elena Bystrai ${ }^{2}$, Yuliya \\ Raisvikh ${ }^{2}$, and Tatyana Shtykova ${ }^{2}$ \\ ${ }^{1}$ Ural Federal University, Ekaterinburg, Russia \\ ${ }^{2}$ South-Ural State Humanitarian Pedagogical University, Chelyabinsk, Russia
}

\begin{abstract}
There are numerous disputes and discussions about the need to introduce online learning technologies into the educational process of the university. However, the welcoming examples of individual educational institutions should not give rise to the illusion of complete and widespread prosperity. In many Russian universities, the situation with the introduction of new teaching aids is, to put it mildly, difficult both in terms of the availability of an organizational strategy and in terms of cultural changes. The article attempts to characterize the situation with online education in universities based on an analysis of the expectations of students who seem ready to move to digital, and the decisions of the Bologna process, requiring the introduction of online components in the educational process of universities. In addition, the authors of the article provide an overview of the initial attempts to introduce online learning into the educational process of universities in a particular region, taking into account the systematic and psychological difficulties that have arisen. As the best option, the authors propose a combination of online education with a research component in order to preserve the university's status as a center of science and education.
\end{abstract}

\section{Introduction}

The Bologna process, internationalization and leading positions in scientific and technological development are the main problems of concern to all specialists in the higher education system. Of no small importance are the problems of the quality of education, more effective support of students and more intensive implementation of new teaching aids in the educational process. In most cases, the focus of all the problems described is the desire to reduce the share of state funding for scientific and technological development and attract investment from private companies and individuals interested in relevant research. Given a certain limited state financial injections into the budgets of universities and the growing confidence in the public consciousness that universities should work more efficiently, today the risk of falling into the background of the main purpose of universities - science and education - remains.

\footnotetext{
* Corresponding author: nellik1983@mail.ru
} 
Economic thinking and pragmatic activity, flexibility and a certain pace - not every modern university is able to abandon the traditional education model in favor of the aforementioned requirements. Obviously, the stated requirements are also valid in relation to online education, giving rise to a number of questions and conjectures, among which one can name the definition of the boundaries of the online component, its effectiveness, possible consequences, etc. We are of the opinion that the result will be an alliance of a defined culture and strategy that will help universities maintain their status as centers of science and education.

Currently, a number of initiatives are being implemented in our country aimed at creating the necessary conditions for the development of the digital economy in Russia, which increases the country's competitiveness, the quality of life of citizens, ensures economic growth and national sovereignty. First of all, these are the "Strategy for the Development of the Information Society in the Russian Federation for 2017 - 2030" and the Program "Digital Economy of the Russian Federation".

Without a doubt, modern Russian students are at the origins of the digitalization of the entire higher education system. It is obvious that the current challenges will force universities to seriously address the issue of online learning. The only question is which direction this topic will take.

\section{Methodology}

In the summer of 2017, the Ministry of Education and Science of the Russian Federation held a competition among Russian universities to develop elements of an educational platform. Among the winners of the competition were the country's leading universities: Moscow State University named after M.V. Lomonosov, ITMO University, UrFU, Tomsk State University, Far Eastern State University and others.

According to the results of the competition, the leading universities of the country, in accordance with the stated mission, have been introducing online technologies into the educational process over the past few years, using digital as a means of improving the quality of education, as an effective combination of scientific, technological and educational components, as a center of strategic decisions.

In particular, on the basis of the Ural Federal University named after the first President of Russia B.N. Yeltsin, by the order of the rector of November 21, 2019, the Center for Digital Transformation was created, the main goal of which is to develop and implement the University Digital Transformation Program. Employees of the Center for Digital Transformation oversee the development of the concept, implementation and assessment of the results of online learning in the educational process of the university in close cooperation with representatives of the classical didactics of higher education.

As part of its activities, the Center for Digital Transformation of UrFU develops and implements online courses for employees in order to form their key competencies for the digital economy in accordance with the Federal Program "Human Resources for the Digital Economy" of May 28, 2019. Representatives of various branches of science become the listeners of these courses: physicians and veterinarians, engineers and biologists, as well as philologists and sociologists - questions and problems of online learning affect and arouse the interest of all representatives of the scientific community. Based on this, the range of tasks of the employees of the Center for Digital Transformation of UrFU includes:

1) information, communication and social work;

2) development of cooperation with representatives of other leading universities;

3) administration and quality assessment of the process implementation;

4) technical and organizational development. 
Thus, the process of digitalization of education is associated not only with the mission of the university, but also represented and actively developed in all its structural divisions.

The modern world scientific community has an impressive potential for the implementation and dissemination of online learning. In our opinion, the position of German scientists S. Soyfert and D. Oyler deserves special attention [Seufert S., Oyler D. Sustainable development of innovative processes in the field of e-learning: research in the field of strategies for implementing e-learning as innovations at the university. Access mode: http: /www.scil.ch/publications/docs/2005-01-seufert-euler-nachhaltigkeit-elearning.pdf (Date of access: 07/15/2020)], offering a number of strategies for the implementation of online learning in the educational process of the university:

1) professionalization strategy

(the main goal of online learning is to optimize and modernize the learning process, leading to the creation of a new management system of the educational process);

2) flexibilization strategy

(the main goal of online learning is to individualize the learning process and focus on the requests and needs of students);

3) reformation strategy

(online learning is used as an impetus for radical changes, for example, to change the paradigm of the entire educational process or to proactively present the culture of learning and education);

4) marketing strategy

(online training contributes to the disclosure of new market potentials, primarily in the field of continuing education and the development of new business ideas).

So, it is obvious that the first two strategies (professionalization and flexibilization) are designed to optimize or improve the existing state of the education system. The third and fourth strategies (reforming and marketing) are aimed at introducing and developing something new that did not previously exist in the education system.

Conducted analysis [Seufert S., Oyler D. Sustainable development of innovative processes in the field of e-learning: research in the field of strategies for the implementation of e-learning as innovation in the university. Access mode: http: /www.scil.ch/publications/docs/2005-01-seufert-euler-nachhaltigkeit-elearning.pdf (Date of access: 07/15/2020)] allowed us to highlight a number of key characteristics required for a university and the implementation of online learning:

1) first of all, the technical readiness of the university should be highlighted, in accordance with which a decision is made on the use of a centralized learning platform or an online complex, consisting of a certain platform and social means of communication, as the basis for online learning; alternatively, a reimbursable private training platform can also be used;

2) the economic capabilities of the university assess the online learning process from the standpoint of mastering new areas of commercial activity and new electronic channels for the sale of educational services; at the same time, financial capabilities and the ratio of costs and incomes from online education are analyzed;

3) structural characteristics of the university - the possibility of creating new structures, services and departments for the comprehensive support of the online learning process; achieving a balance between centralization and decentralization depending on the size and diversity of the university;

4) socio-cultural characteristics of the university - support from the leadership of the university, the creation of a network of branches, an active information policy, advanced training of employees, comprehensive support and incentives;

5) the didactic strategy of the university forms the core of the university digitalization process and consists in multimedia equipment, the organization of the stages of the 
educational process on the basis of various forms of digital communication, as well as the general didactic design of training courses or educational programs;

Summing up the above, it should be emphasized that everything related to the key characteristics of the university, necessary for the successful implementation of online learning, depends on a number of conditions, such as the external environment and strategic positions of the university, the size and diversity of the university, as well as the habits and preferences of those involved in the process. digitalization of employees and students. The main goal is to introduce online training on an ongoing basis with the lowest psychological costs for all participants in the process. An essential condition for this process is also support from the university leadership, regional and federal authorities, as well as an active system of structural changes and strict adherence to the University's Mission.

\section{Results}

So, the winners of the competition among Russian universities for the development of elements of the educational platform, organized by the Ministry of Education and Science of the Russian Federation in 2017, can rightfully be called the pioneers in the field of introducing online learning into the educational process. These are universities that recognize the critical importance of the digital transformation of the Russian higher education system and offer various forms of online education, including virtual support of a full-time study format, blended learning, as well as online seminars or entire educational programs online.

In our opinion, among the above-mentioned "pioneers" are:

1) theoretical universities - universities that attach high importance to online learning, but in fact practically do not provide educational services online, at best, virtual support of the full-time training format;

2) skeptical universities - universities that have doubts about the effectiveness of online learning and have a few online courses in their arsenal;

3) pragmatic universities - universities that consider online learning ineffective, while offering a variety of forms of online learning.

Let us now turn to the staff of the pioneering universities. What is their attitude to the ongoing changes? After all, these changes are implemented "by their hands." In this regard, we propose to conditionally divide the employees of the universities-winners of the competition for the development of elements of the educational platform into four groups, namely:

1) enterprising employees, internally motivated to introduce online technologies into the educational process of the university, ready to experiment with new teaching aids, not expecting any support from the university, but in the absence of recognition from the management, they step aside;

2) cautious employees do not want to get involved in the digitalization process of the university, they are afraid of risky experiments and are waiting for appropriate support technical and personal;

3) career employees do not show themselves as clear opponents, however, they are included in the digitalization process only in the case of an objective benefit for their own career;

4) opponent employees feel a clear superiority of technical means over themselves, while being supporters of the fact that everything new and modern is not good for anything.

Unfortunately, we do not have accurate data on the numerical distribution of the abovementioned types among university employees. However, the first data on the reaction of Russian universities to the trend of digitalization of education have already been obtained. Most universities are in a state of expectation, and more from their plans than from actual actions; a few universities consider themselves to be pioneers or pioneers in the field of 
digital transformation, while many universities are skeptical about this issue. Both globally in the higher education system and among its individual employees, there are different points of view and attitudes towards online learning. There are also pioneers and doubters, expectant and active attitude and various motives.

\section{Conclusions}

A survey conducted among students of UrFU in May 2020 showed the following results:

1. Students for the most part have certain requirements for online learning. About $90 \%$ of respondents have access to the network at home, more than half of them have a highspeed connection; almost all the students who took part in the survey have the skills to work with e-mail and search engines on the Internet;

2. $86 \%$ of the surveyed students are familiar with online technologies and platforms and actively use them in educational activities, provided they are of high quality; $80 \%$ of the total number of those who took part in the survey are familiar with and use online learning technologies that ensure the process of full-time education - the first stage of the transition to digital in the Russian education system.

Online technologies, the structure and content of which have been mastered by the majority of students of Russian universities, unfortunately, does not yet fully and effectively provide educational activities and the learning process. However, it can be argued for sure that new media have become a familiar means of teaching, for which students have formed the necessary skills and abilities.

The digitalization of the education system has become the subject of numerous modern studies in Russian science. Numerous studies have been prepared, on the basis of which Models of the digital educational environment have been developed, designed to promote the introduction of online learning technologies at a high professional level.

Successful implementation of the priority project "Modern digital educational environment in the Russian Federation" will radically change the approach to teaching citizens of the country; prepare Russia for the transition to a new technological structure - to the digital economy.

\section{References}

1. A.A. Andreev, Internet Technologies in Higher Schools: Current State and Problems, Higher Education in Russia, 12, 29-33 (2009)

2. A.A. Andreev, The Role and Problems of the Teacher in E-Learning Environment, Higher Education in Russia, 8/9, 41-45 (2010)

3. A.A. Andreev, Pedagogy in the Information Society, Higher Education in Russia, 11, 113-117 (2011)

4. Moscow E-Learning Centre: EDX as the Smartest MOOC Platform in the American Distance Education, URL: http://bakalavr-magistr.ru/news/177

5. Yu.R. Petkova, The History of the Development of Distance Education. The Positive and Negative Sides of the MOOC, Advances in Current Natural Sciences, 3, 199-204 (2015), URL: http://natural-sciences.ru/ru/article/view?id=34763

6. M.M. Pyannikov, On the History of Distance Education, Pedagogy and Psychology, 5, 119-123 (2011)

7. S.L. Timkin, Udacity as a Troublemaker in the System of US Higher Education, Institute of Continuing and Open Education, Omsk F. M. Dostoevsky State University, URL: http://omsu.ru/page.php?id=4137 
8. A.N. Khuziakhmetov, R.R. Khuziakhmetov, Student's Studying Action in High School on the Stage of the Transition to Distance Education, Higher Education in Russia, 4, 98102 (2012)

9. A.S. Shapovalov, From "E-LEARNING" TO "E-LEARNING 2.0" and "MASSIVE OPEN ONLINE COURSES": Development of On-line Education, Int. J. of Experimental Education, 7, 52-55 URL: http://www.rae.ru/meo/ ?section=content\&op=show_article\&article_id=5551 (2014)

10. M. Aspillera, What Are the Potential Benefits of Online Learning?, Education Guidance. URL: $\quad$ http://www.worldwidelearn.com/education-articles/benefits-of-onlinelearning.htm (WorldWideLearn, August 5, 2010)

11. B. Means, Y. Toyama, R. Murphy, M. Bakia, K. Jones, Evaluation of evidence-based practices in online learning: A meta-analysis and review of online learning studies, US Department of Education (2009)

12. G. Miller, History of Distance Learning, Education Guidance, American Inter Continental University Online, URL: http://www.worldwidelearn.com/educationarticles/history-of-distance-learning.html (November 10, 2014)

13. D. J. Rosen, C. Stewart, Blended learning for the Adult Education Classroom (2013)

14. R. Tenberg, Linking learning and assessment: Cambridge ESOL's blended learning approach, Cambridge ESOL Research Notes, 36, 18-22 (2009)

15. S. Writers, 10 Advantages to Taking Online Classes. Open Education Database. URL: http://oedb.org/ilibrarian/10-advantages-to-taking-online-classes/ (December 12, 2012) 